\title{
Flow of a Cross-Linking Polymer in Porous Media
}

\author{
N. Lenchenkov ${ }^{1}$ (D) $\cdot$ G. Glasbergen ${ }^{2} \cdot$ C. van Kruijsdijk $k^{1,2}$
}

Received: 13 September 2016 / Accepted: 6 June 2018 / Published online: 11 July 2018

(c) The Author(s) 2018

\begin{abstract}
Heterogeneous reservoirs often have poor sweep efficiency during flooding. Although polymer flooding can be used to improve the recovery, in-depth diversion might provide a more economical alternative. Most of the in-depth diversion techniques are based on the propagation of a system that forms a gel in the reservoir. Premature cross-linking of the system prevents the fluid from penetrating deeply into the reservoir and as such reduces the efficiency of the treatment. We studied the effect of using a polyelectrolyte complex (PEC) to (temporarily) hide the cross-linker from the polymer molecules. In addition to studying the cross-linking process in bulk, we demonstrated its behaviour at the core scale ( $1 \mathrm{~m}$ length) as well as on the pore scale. The gelation time in bulk suggested that the PEC could effectively delay the time of the cross-linking even at high brine salinity. However the delay experienced in the core flood experiment was much shorter. Tracer tests demonstrated that the XL polymer, which is a mixture of PEC and partially hydrolyzed polyacrylamide, reduced the core pore volume by roughly $6.2 \%$ (in absolute terms). The micro-CT images showed that most of the XL polymer was retained in the smaller pores of the core. The large increase in dispersion coefficient suggests that this must have resulted in the creation of a few dominant flow paths isolated from each other by closure of the smaller pores.
\end{abstract}

Keywords Flow of polymers in porous media · Tracer test · Computed tomography · Polyelectrolyte complex

\section{Abbreviations}

$\begin{array}{ll}\text { PEI } & \text { Polyethyleneimine } \\ \text { PEC } & \text { Polyelectrolyte complex } \\ \text { KI } & \text { Potassium iodide } \\ \text { CT } & \text { Computed tomography } \\ \text { HPAM } & \text { Partially hydrolyzed polyacrylamide } \\ \text { XL polymer } & \text { Cross-linking polymer: a mixture of PEC and HPAM }\end{array}$

N. Lenchenkov lenchenkovn@gmail.com

1 Delft University of Technology, Stevinweg 1, 2628 CN Delft, The Netherlands

2 Shell Global Solutions International, Grasweg 31, 1031 HW Amsterdam, The Netherlands 


$\begin{array}{ll}\text { XL agent } & \text { Cross-linker } \\ \text { PV } & \text { Porous volume } \\ \text { UV } & \text { Ultraviolet } \\ \text { ICP } & \text { Inductively coupled plasma spectrometry } \\ \mathrm{Mw} & \text { Molecular weight } \\ \mathrm{HCl} & \text { Hydrochloric acid } \\ \mathrm{NaClO} & \text { Sodium hypochlorite } \\ \text { AddiDict } & \text { Module of the Geodict software that computes advection and diffusion through } \\ & \text { porous materials } \\ \text { WOR } & \text { Water-oil ratio }\end{array}$

\section{Introduction}

In-depth profile modification is a promising technology for improving the sweep efficiency of water flooded heterogeneous oil reservoirs (Seright et al. 2011; Sydansk and Southwell 2000; Bailey et al. 2000; Glasbergen et al. 2014). It can be implemented by injecting a crosslinking polymer (XL polymer) that propagates deep into the reservoir. The viscosity of the polymer has to be low for some period of time followed by a fast viscosity build-up as it reaches the gel point (Winter 1987; An et al. 2010; Dickie et al. 1988). The formed gel has a high apparent viscosity (approx. 15,000 cP) which reduces the effective permeability of layers with higher conductivity (Fig. 1). Once the target zone permeability is reduced, brine flow from injection wells will be diverted into zones with lower permeability (and higher oil saturation). As a result, the production of excessive water will be reduced (WOR-water-oil ratio) and oil production will be increased (Fig. 2). The efficiency of the process depends on the geological characteristics of the reservoir, the physical properties of the cross-linking polymer, its concentration in the target zone and the interaction with the minerals of the rock (Seright et al. 2011; Bailey et al. 2000; Glasbergen et al. 2014; Lake 2010).

The most appropriate chemical system for in-depth profile modification in a reservoir should have the following properties: tolerance to the salinity of the brine, thermal stability, low initial viscosity, deep propagation into a reservoir, and low mechanical degradation (Karsani et al. 2014; Zhang and Zhou 2008; Zitha et al. 2002). There are a few XL polymers that can meet the desired requirements for profile modification problems in specific reservoir conditions (Sydansk 1988; Vasquez et al. 2003; Crespo et al. 2014). One of the commonly

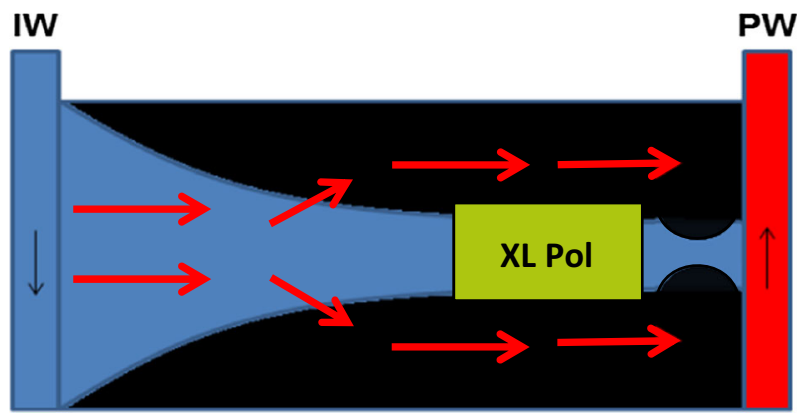

Fig. 1 Diversion of the injected water in the reservoir after it was treated with the XL polymer: IW-injection well; PW—production well 
Fig. 2 An example of the change in water-oil ratio over time before and after the reservoir is treated with the XL polymer

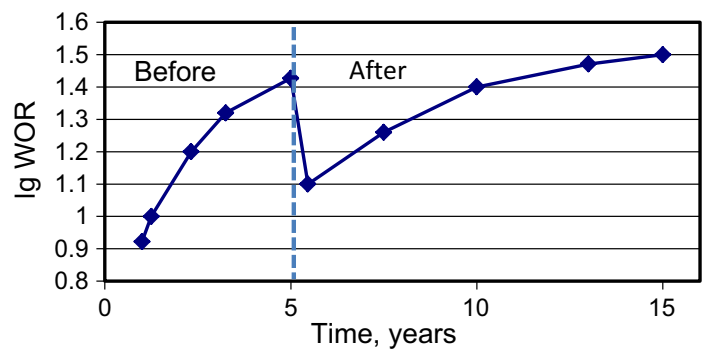

applied cross-linking systems is a mixture of a hydrolysed polyacrylamide (HPAM) and polyethylenimine (PEI) (Al-Muntasheri et al. 2008; Crespo et al. 2013). Despite its frequent application, there is a lack of knowledge about the in situ dynamic cross-linking of such systems and hence the efficiency of the XL polymer cannot be predicted from reservoir to reservoir. Therefore, it is important to study the in situ dynamic cross-linking of polyacrylamide both from a theoretical as well as from a practical point of view. Cross-linking of HPAM often happens fast (2-4 days) (Glasbergen et al. 2014). In general this is not acceptable for the purpose of injecting a XL polymer deep into a reservoir. In order to extend the gelation time it is desired to make a cross-linker, which is a polycation, less active by mixing it with a retardant, polyanion. As a result of that reaction, a polyelectrolyte complex (PEC) is formed (Cordova et al. 2008; Müller et al. 2011; Spruijt 2012; Jayakumar and Lane 2012). Over time the chemical bonds between the polycation and the polyanion become weaker and the cross-linker becomes available for interaction with HPAM. In the current work, a PEC was employed for delaying the reaction between HPAM and PEI. The flow of this mixture in porous media was studied experimentally according to a specially developed framework. That framework includes bulk, pore scale, as well as a core flood experiment. The bulk rheology of different XL polymer recipes was tested first to select a relevant recipe with a gelation time suitable for the core flood experiment. There are different parameters which influence the kinetics of cross-linking of the polymer: temperature, different concentration of divalent ions, and cross-linker concentration. These parameters were varied during the bulk tests to meet the following requirements: (1) the initial viscosity of a mixture (polymer + cross-linker) has to be low and the gelation time not less than 5 days; (2) the XL polymer has to be stable at $45^{\circ} \mathrm{C}$, which is the target temperature of the experiment; (3) no dramatic precipitation occurs during the gelation time.

Next, a slug of the selected XL polymer was injected into a 1-m Boise core and it was subsequently displaced by HPAM in order to study the in situ dynamic cross-linking of the polymer. During the injection process, the pressure drop over the core was recorded. To understand the reason for the pressure drop build-up during the injection of the XL polymer into the core, a series of filtration tests was carried out. Filters with 3 different pore sizes were used in the test to study the size of the cross-linking particles which are formed during the cross-linking reaction. In addition to that, porosity reduction and the change in the dispersion coefficient were obtained by the injection of a tracer into the core (before and after XL polymer injection). Tracer transport in porous media was modelled by fitting an experimental breakthrough curve for a tracer with a one-dimensional advection-dispersion model, where porosity and dispersion are matching parameters (Sorbie 1991; van der Hoek et al. 2001; Seetha et al. 2014). The two tracer tests show a porosity reduction of $6 \%$ and an increase in the dispersion coefficient by a factor of 20 which indicates that the in situ cross-linking took place in the porous media. 
Distribution of the polymer gel in the porous medium was studied by micro-computed tomography of core samples which were drilled out from the 1-m core after the experiment was finished (van Krevelen and te Nijenhuis 2008; Hove et al. 1990; Turner et al. 2004; Saadatfar et al. 2005; Al-Muntasheri et al. 2008). The distribution of the polymer can explain the change in the dispersion coefficient. The size of a sample is $4-10 \mathrm{~mm}$, and it was taken after the core was treated with the XL polymer. The results show that the polymer is concentrated mostly in the smaller pores of the samples. Pore-scale modelling of a non-reactive tracer flow was done in a three-dimensional image of the rock using Addict software to show the difference in the tracer breakthrough time. That allowed for obtaining the dispersion coefficient after the gel was formed in the core.

\subsection{Experimental Material and Procedures}

\subsubsection{Bulk Experiments}

Selection of the XL polymer recipe for the core flood experiment was done via the study of the gelation time and gel stability. As mentioned before, we used the following criteria to select the recipe to be used in the core floods:

1. low initial viscosity of the mixture (polymer + cross-linker);

2. gelation time of more than 5 days;

3. stable at elevated temperatures;

4. no dramatic precipitation over time.

HPAM with PEI as a cross-linker was selected for this study. The reaction between HPAM and PEI can be explained as imine nitrogen from PEI attacking the carbonyl carbon attached to the amide group of the polymer (Fig. 3) (Jia et al. 2010). That creates chemical bonds which are much stronger than ionic bonds.

The thermal stability of this system over a wide range of temperatures is ensured by the resulting covalent bonding (Moradi-Araghi and Stahl 1991; Hutchins et al. 1996).

Activation of the XL polymer deep in the reservoir requires a delay in the reaction between the polymer and the cross-linker. Consequently, the polymer needs to be (temporarily) shielded from the cross-linker. Polyelectrolyte complexes (PEC) have shown their effectiveness for entrapping and delivering small molecules (large proteins) while maintaining colloidal stability via electrostatic repulsion (Fig. 4).

A polyanion (e.g. dextran-sulphate) together with the organic polycation cross-linker PEI can form a nanoparticle polyelectrolyte complex by self-assembly through electrostatic intermolecular interactions (Müller et al. 2011). In time, the PEC particle will unfold, releasing the cross-linker.

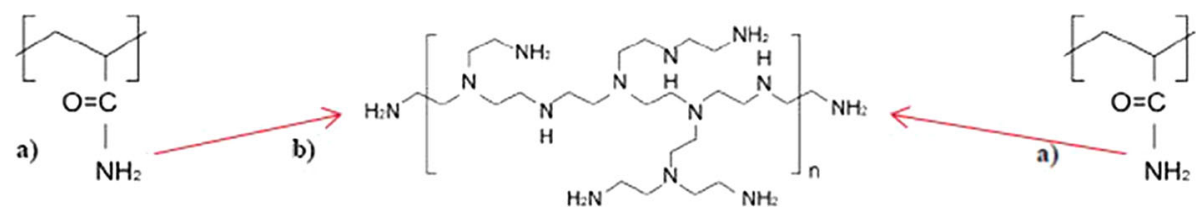

Fig. 3 Chemical structures of polymers: a-carbonyl carbon group of HPAM; b-PEI 


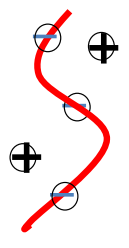

Polyanion

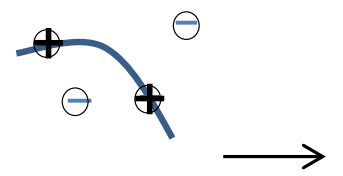

Polycation PEI

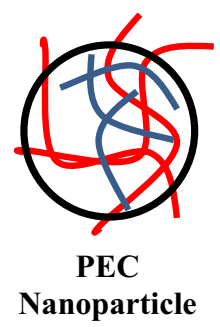

Fig. 4 Sketch of PEC formation from PEI and an appropriate polyanion

Table 1 Brine compositions

\begin{tabular}{|c|c|c|c|}
\hline \multicolumn{2}{|l|}{ Type 1} & \multicolumn{2}{|l|}{ Type 2} \\
\hline Ions & Concentration (mg/l) & Ions & Concentration $(\mathrm{mg} / \mathrm{l})$ \\
\hline $\mathrm{Na}^{+}$ & 1656 & $\mathrm{Na}^{+}$ & 1519 \\
\hline $\mathrm{K}^{+}$ & 28 & $\mathrm{~K}^{+}$ & 871 \\
\hline $\mathrm{Mg}^{+2}$ & 11 & $\mathrm{Mg}^{+2}$ & 77 \\
\hline $\mathrm{Ca}^{+2}$ & 24 & $\mathrm{Ca}^{+2}$ & 491 \\
\hline $\mathrm{Cl}^{-}$ & 2534 & $\mathrm{Cl}^{-}$ & 4108 \\
\hline $\mathrm{SO}_{4}^{-2}$ & 159 & $\mathrm{SO}_{4}^{-2}$ & 159 \\
\hline
\end{tabular}

\subsubsection{The Preparation Procedure for the XL Polymer Samples}

We prepared a total of 16 different recipes by altering the following parameters:

1. divalent ions concentration $\left(\mathrm{Ca}^{+2}, \mathrm{Mg}^{+2}\right)$ ( 2 different brines to validate robustness);

2. temperature of the test $\left(30,45,60,85^{\circ} \mathrm{C}\right)$;

3. cross-linker concentration $(754,3077 \mathrm{mg} / \mathrm{l})$.

Initially two HPAM stock solutions were prepared by dissolving a polyacrylamide pow$\operatorname{der}\left(\mathrm{Mw}=20 \times 10^{6} \mathrm{D}\right)$ in two types of brine, which differ by divalent ions concentration (Table 1). Brine type 2 contains a 20 times higher concentration of $\mathrm{Ca}^{2+}$ compared to the brine type 1 . The polymer solution was stirred for $48 \mathrm{~h}$ to achieve a complete dissolution of the polymer. Subsequently, the prepared stock solution was filtered to remove impurities using a $5-\mu \mathrm{m}$ Millipore filter.

The components of the PEC were diluted in demineralized water separately (Table 2). The hydrogen-ion concentration of the PEI solution was adjusted by using concentrated $\mathrm{HCl}$ to a $\mathrm{pH}$ of 10.7. Subsequently, PEI and polyanion were mixed together while stirred at $600 \mathrm{rpm}$. In order to avoid polymer degradation, the samples were prepared in a glove box maintaining an oxygen-free environment (Sorbie 1991).

\section{Study of a XL Polymer Gelation Time}

The gelation time, indicative of the cross-linking kinetics, was studied using a falling ball viscometer. Although that approach is less accurate than a small amplitude oscillatory shear test, it gives a good indication of viscosity increase over the time. Moreover, this approach 
Table 2 Initial concentrations of the chemicals in the selected XL polymer

\begin{tabular}{lcc}
\hline Component & Molecular weight, $10^{3} \mathrm{D}$ & Concentration (mg/l) \\
\hline HPAM & 20,000 & 2500 \\
PEI (XL agent) & 25 & 754 \\
Polyanion (retardant) & 5 & 151 and 313 \\
\hline
\end{tabular}

is very efficient and allows assessment of a large number of samples in a short time. The test requires a long glass tube that is completely filled with a XL polymer. The viscosity can be estimated from the time it takes for the ball to fall to the bottom according to Eq. 1 (Batchelor 2000):

$$
\mu=\frac{g \cdot d^{2}}{18 l} \cdot\left(\rho_{s}-\rho_{f}\right) \cdot t
$$

where $\mu$ (Pa s) — viscosity, $t(\mathrm{~s})$ - time, $\mathrm{s}, \mathrm{f}\left(\mathrm{kg} / \mathrm{m}^{3}\right)$ — densities of the glass ball and fluid, respectively, $l(\mathrm{~m})$ - length of a tube, $d(\mathrm{~m})$ - diameter of the ball, and $g\left(\mathrm{~m} / \mathrm{s}^{2}\right)$ - gravitational acceleration.

\section{Core Flood Experiment}

In order to study the in situ cross-linking of HPAM, a core flood experiment was done. The core flood set-up (Fig. 5) has a core holder (1) designed for a 1-m core covered by a rubber sleeve to allow a confining pressure of 50 bar. The core holder is covered by a heating jacket (6), to maintain elevated temperatures during the experiment. The test was run against a back pressure of 5 bar, maintained by a flexible membrane (4) connected to a high pressure nitrogen vessel. The pump (5) is used to inject fluids through a bottom part of the core holder. The pressure drop over the core is measured using a pressure transducer (2) and recorded by the data acquisition system (7) together with the data from temperature sensors and the pump. The effluent collector (3) was used to take samples of the produced brine for further analysis $\left(\mathrm{K}^{+}, \mathrm{Na}^{+}, \mathrm{Ca}^{2+}, \mathrm{Mg}^{2+}\right)$ using an ICP. The experiment consisted of multiple steps as listed in Table 3. Brine type 1 was injected into the core for the XL polymer preparation, as well as for the permeability test.

\section{Results and Analysis}

The bulk viscosity for the different recipes of the XL polymer is presented in Figs. 6 and 7.

It appears from Figs. 6 and 7 that faster cross-linking of HPAM occurs at higher concentrations of divalent ions. However, the faster cross-linking at higher brine salinities is unexpected because the higher ionic strength results in a smaller radius of gyration (Sorbie 1991; Jia et al. 2010; Glasbergen et al. 2014). That makes negative sites of the polymer less accessible to the cross-linking molecules. Nevertheless, two possible explanations of the faster cross-linking are given in the literature:

1. weaker links between PEI and the retardant at high salt concentrations, which makes PEI available for cross-linking with HPAM 


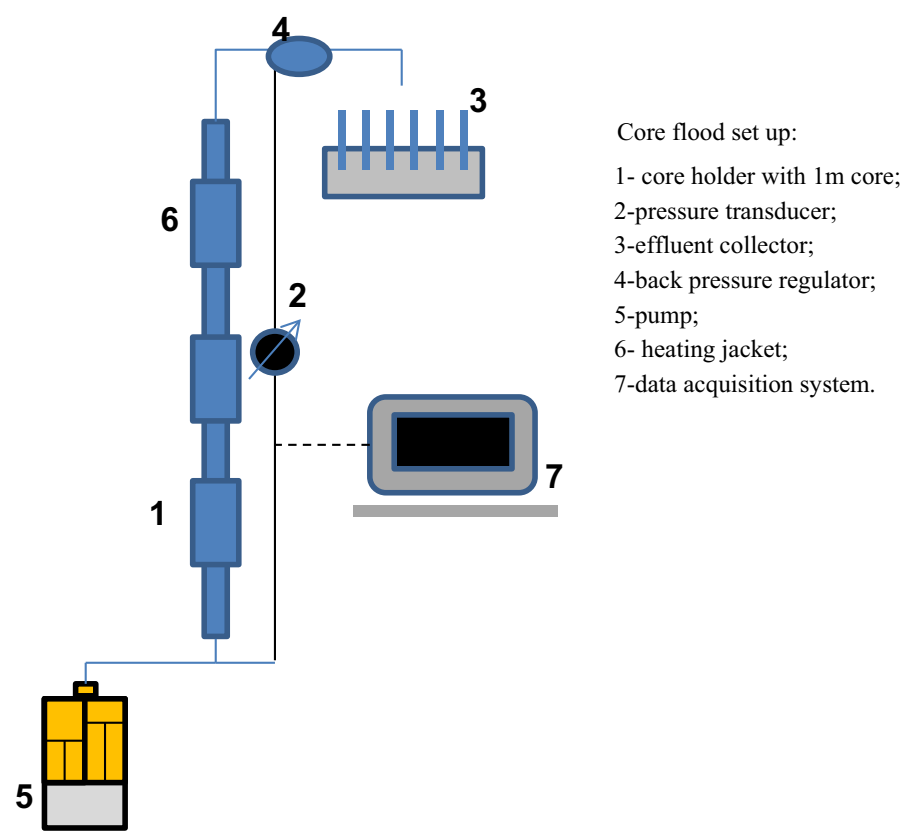

Fig. 5 Core flood set-up: 1 -core holder with 1 m core; 2 - pressure transducer; 3 -effluent collector; 4 -back pressure regulator; 5-pump; 6-heating jacket; 7—data acquisition system

2. the interaction of divalent ions and carboxylic groups is more complex-an interconnection of multivalent cations $\left(\mathrm{Ca}^{2+}, \mathrm{Mg}^{2+}\right)$ with HPAM chains occurs (Zhang 2008).

Additional experiments are required to better understand the chemistry/physics of the reaction.

Faster cross-linking is also observed in the case of a higher weight ratio of the PEI to retardant. The mechanism of a faster gelation at lower concentrations of the retardant can be explained by the availability of free PEI in the beginning of the chemical reaction. Higher temperatures result in faster cross-linking as well.

Based on these results, the fluids selected for the core flood experiment contain the following components: HPAM (2500 ppm), PEI (754 ppm) and polyanion (151 ppm).

As stated earlier, the falling ball viscometer is a quick screening method to determine the gelation time of the XL polymer. To obtain a more accurate estimate of the viscosity (including its shear rate dependence), a rotation viscometer was used (Fig. 8).

Results of the rheology experiments carried out at $45^{\circ} \mathrm{C}$ show that the initial viscosity of the XL polymer is $88 \pm 3 \mathrm{cP}$ at $7 \mathrm{~s}^{-1}$, and it is equal to the viscosity of polymer (Fig. 8). Due to the cross-linking of the polymer, the increase in the bulk viscosity happens over time. However, due to the presence of the polyanion in the fluid, the active cross-linking in the bulk is delayed. From the figure, it can be seen that the increase in the viscosity is observed after $144 \mathrm{~h}$ of the reaction. The result is in agreement with the results obtained from the falling viscometer method (Fig. 7).

The rheology of the XL polymer can be affected by polymer degradation leading to a reduction in viscosity. To validate the polymer stability, separate rheology tests of the polymer (2500 ppm) were carried out at different ageing time steps (Fig. 9). Results of the 


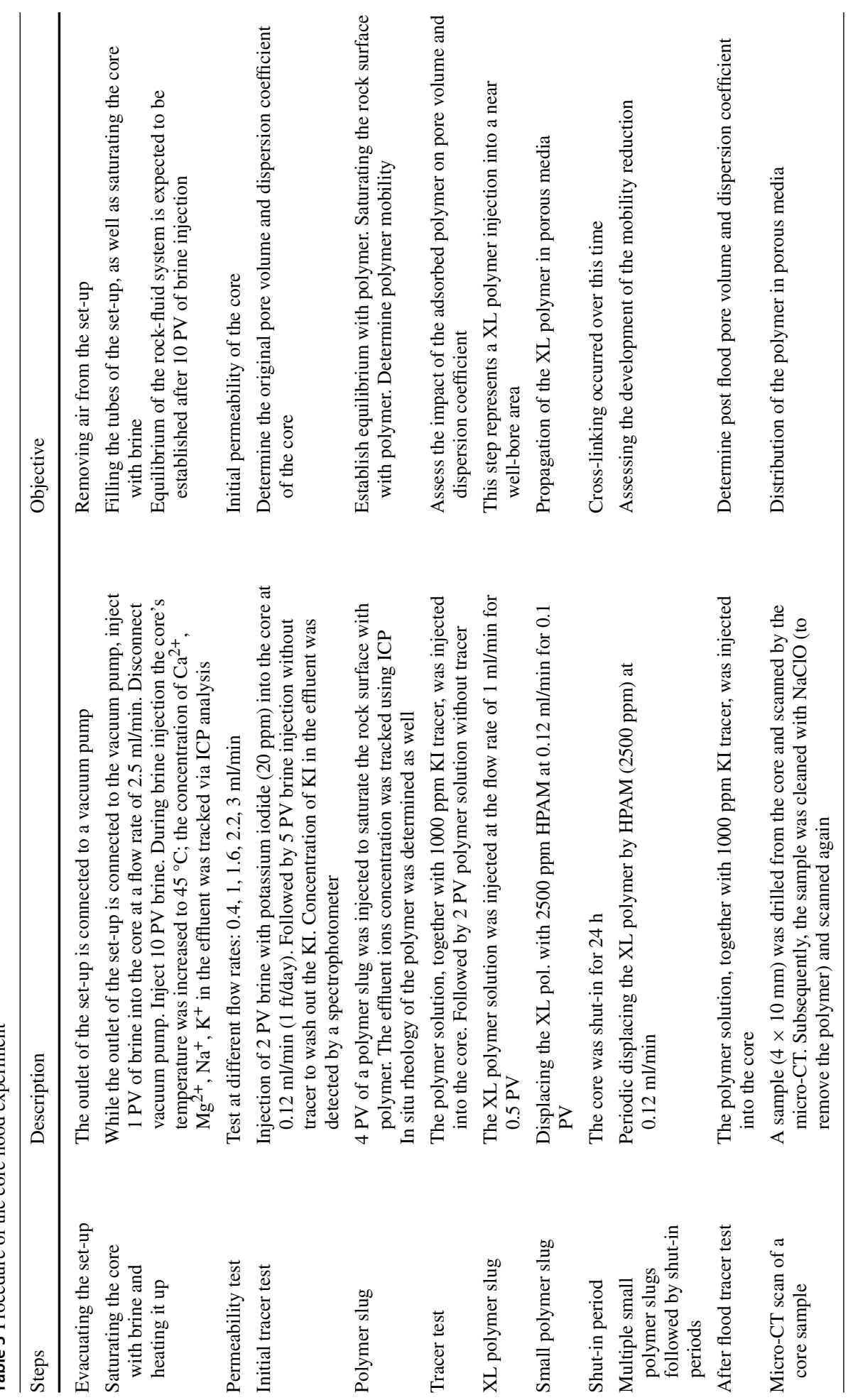




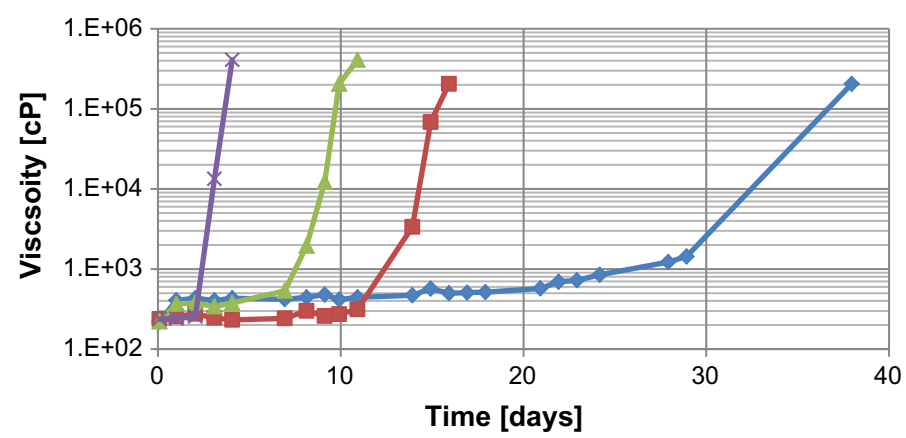

PEI754+PA151+ HPAM at $30^{\circ} \mathrm{C}$, Brine type 1
- PEI754+PA151+ HPAM at $30^{\circ} \mathrm{C}$, Brine type 2
$\times$ PEI754+PA151+ HPAM at $45^{\circ} \mathrm{C}$, Brine type 1
PEI754+PA151+HPAM at $45^{\circ} \mathrm{C}$, Brine type 2

Fig. 6 Viscosity of the HPAM/PEC solutions at different brine compositions (types 1 and 2) and temperatures $\left(30\right.$ and $\left.45^{\circ} \mathrm{C}\right)$

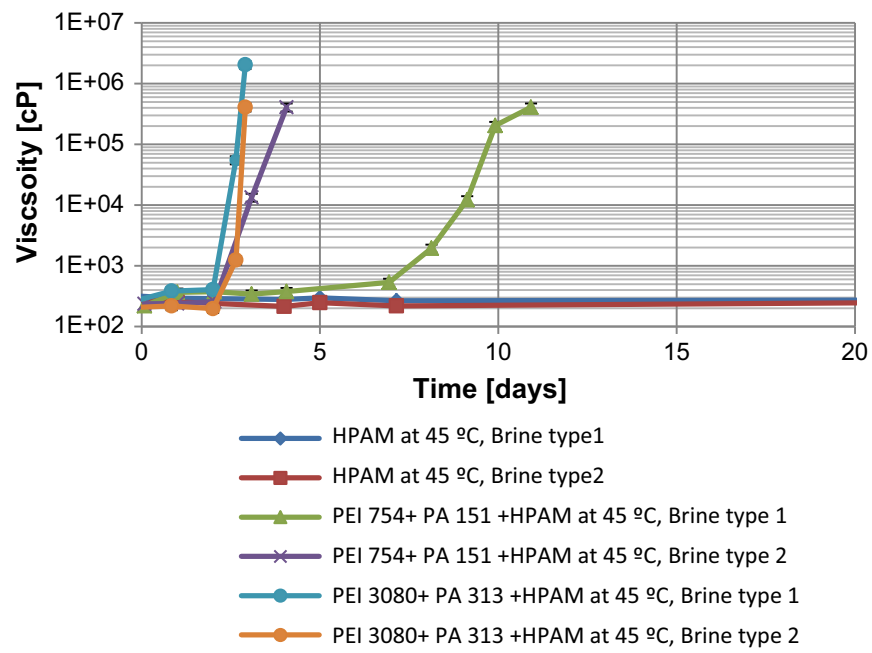

Fig. 7 Viscosity of the HPAM/PEC solutions at different brine compositions (types 1 and 2) at $45{ }^{\circ} \mathrm{C}$

tests show that the polymer maintains its viscosity $83 \pm 3 \mathrm{cP}$ at $7 \mathrm{~s}^{-1}$ for $130 \mathrm{~h}$ of the test period.

\subsection{Brine Injection into the Core}

After evacuating the core, $10 \mathrm{PV}$ of brine was injected to ensure equilibrium between rock and injection brine. The concentrations of various ions $\left(\mathrm{Ca}^{+2}, \mathrm{Mg}^{+2}, \mathrm{Na}^{+}, \mathrm{K}^{+}\right)$in the effluent were measured using the ICP (Fig. 10). During brine injection, after 5.2 PV was injected, the temperature of the core was raised to the target temperature of $45^{\circ} \mathrm{C}$. Note that as the temperature is increased the solution is chemically re-equilibrated. At the end of this phase, 


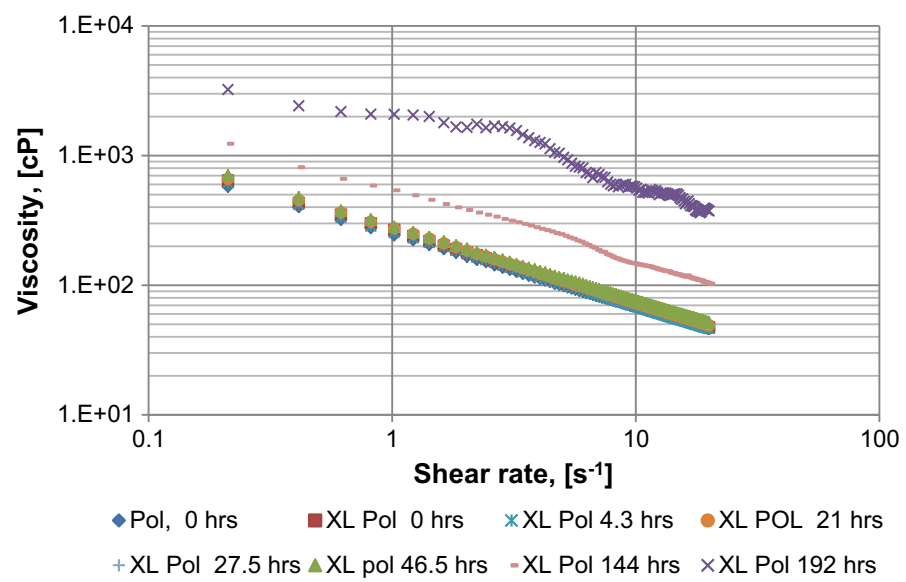

Fig. 8 Viscosity as a function of shear rate for different time steps of the selected XL polymer at $45{ }^{\circ} \mathrm{C}$ (HPAM (2500 ppm), PEI (754 ppm), polyanion (151 ppm) and brine type 1)

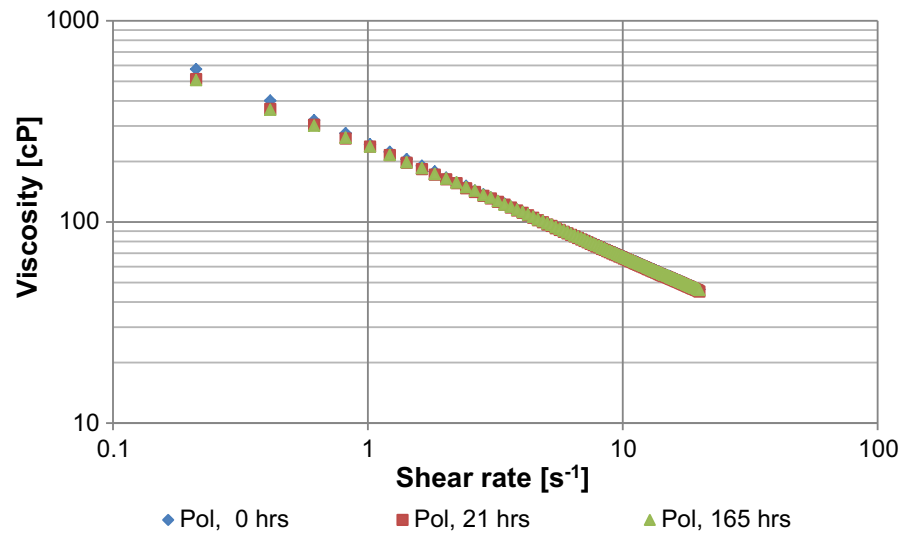

Fig. 9 Viscosity as a function of shear rate at different times (HPAM $2500 \mathrm{ppm}$ ) at $45^{\circ} \mathrm{C}$

$\mathrm{Na}^{+}$and $\mathrm{Mg}^{+2}$ are at the injectant concentration level. The $\mathrm{K}^{+}$and $\mathrm{Ca}^{+2}$ are still somewhat above their equilibrium level.

For the permeability test, 6 different flow rates were employed yielding an estimate of $2.15 \times 10^{-12} \mathrm{~m}^{2}$.

\subsection{Initial Tracer Test}

In order to determine the effective pore volume of the core as well as the dispersion coefficient, $20 \mathrm{ppm}$ of potassium iodide was dissolved in the brine and injected at $0.12 \mathrm{ml} / \mathrm{min}(\sim 1$ $\mathrm{ft} /$ day). The tracer concentration in the effluent was determined using a DR $6000^{\mathrm{TM}} \mathrm{UV}-\mathrm{Vis}$ spectrophotometer set at a wavelength of $226 \mathrm{~nm}$. The results are plotted in Fig. 11. The 


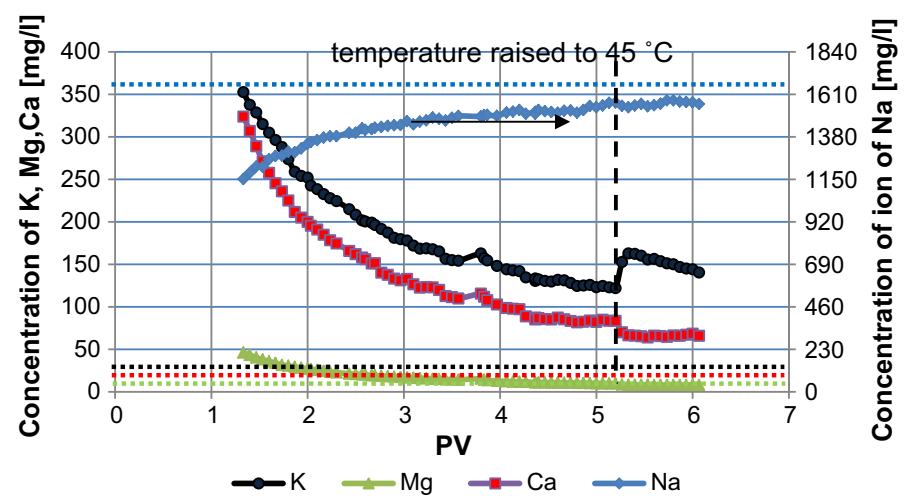

Fig. 10 ICP analysis of the effluent during the brine injection. The dashed lines indicate the concentration of the various ions in the injectant

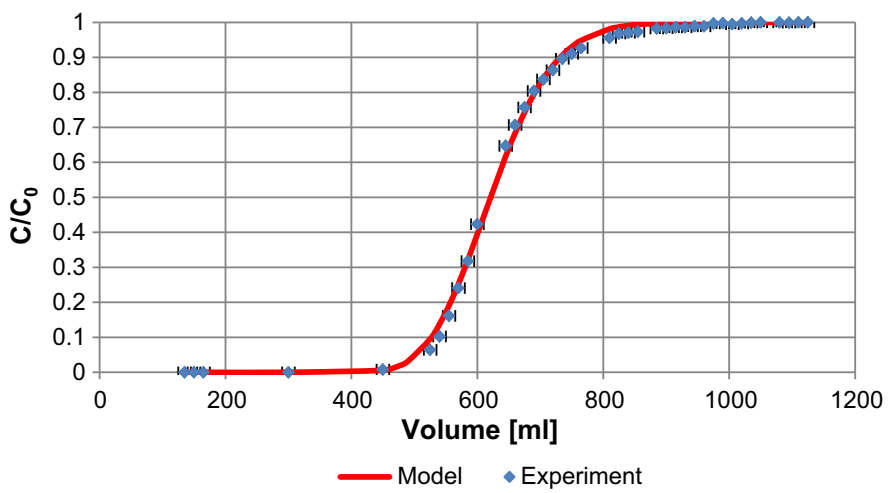

Fig. 11 Initial tracer profile with model fit

tracer test was interpreted by fitting the analytical 1D convection-dispersion solution (Eq. 2) through the data points (Marle 1981; Lake 1996) using an $\mathrm{L}_{2}$-norm.

$$
C_{D}=\frac{1}{2} \operatorname{erfc}\left(\frac{1-t_{D}}{2 \sqrt{\frac{t_{D}}{N_{P e}}}}\right)+\frac{1}{2} \exp \left(N_{P e}\right) \operatorname{erfc}\left(\frac{1+t_{D}}{2 \sqrt{\frac{t_{D}}{N_{P e}}}}\right)
$$

where $C_{D}=\frac{C-C_{1}}{C_{j}-C_{1}}(-)$ - dimensionless concentration, $C_{1}(-)$-initial concentration, $C_{j}$ $(-)$-injection concentration, $L(\mathrm{~m})$ - core length, $N_{P e}=\frac{u L}{\phi D}(-)$-Peclet number, $D$ $\left(\mathrm{m}^{2} / \mathrm{s}\right)$ - dispersion coefficient, $t_{D}=\int_{0}^{t} \frac{q d t}{V_{p}}(-)$-dimensionless time of PV injected, $u$ $(\mathrm{m} / \mathrm{s})$-Darcy velocity, $\mathrm{q}\left(\mathrm{m}^{3} / \mathrm{s}\right)$ - flow rate, $t(\mathrm{~s})$ - time, $V_{p}\left(\mathrm{~m}^{3}\right)$-accessible pore volume, $x_{D}=\frac{x}{L}(-)$ - dimensionless distance, $\phi(-)$ - porosity.

The data match yielded an effective pore volume of $636 \pm 20$ [ml] (porosity $31.8 \pm 1 \%$ ) and a dispersion coefficient of $2.5 \pm 0.6 \times 10^{-4}\left[\mathrm{~cm}^{2} / \mathrm{s}\right]\left(N_{P e}=127 \pm 40\right)$. 

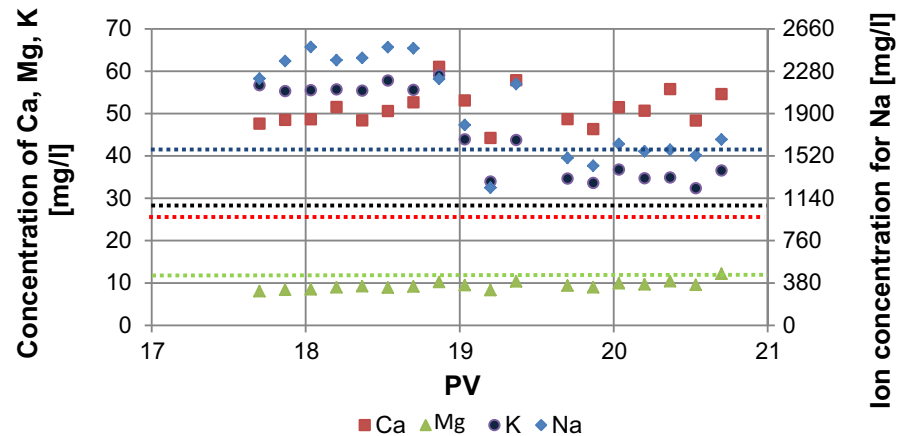

Fig. $12 \mathrm{ICP}$ analysis of the effluent during the polymer injection. The dashed lines indicate the injectant values

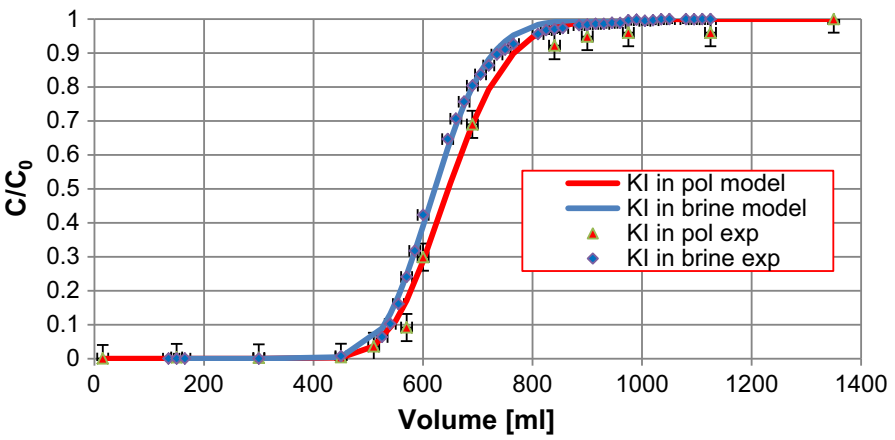

Fig. 13 Tracer concentration in the effluent during brine and polymer injection, including the model fits

\subsection{Injection of the Polymer into the Core}

After 17.6 PV of brine was injected, we switched to the polymer solution and started to saturate the rock surface. ICP analysis of the effluent showed that the $\mathrm{Ca}^{+2}$ and $\mathrm{Mg}^{+2}$ concentrations did not change significantly during this phase of the experiments (Fig. 12). That might be explained by the interaction of the injectant with the rock surface which can favour the dissolution of $\mathrm{Ca}^{+2}$ and $\mathrm{Mg}^{+2}$. This may lead to the high concentration of the ions in the produced fluid. The $\mathrm{Na}^{+}$concentration dropped to the injection value after $2 \mathrm{PV}$ injected. The $\mathrm{K}^{+}$concentration reduced to the value which is slightly above the injectant concentration after $2 \mathrm{PV}$.

Subsequently, the tracer test was repeated. The fluid collected during this step contains the polymer and the tracer in the same testing tubes. In order to avoid interference of the polymer with the tracer analysis, the effluent was diluted by a factor of more than 50. Consequently, a significantly higher injected KI concentration (1000 ppm) was required. Figure 13 shows the results of the tracer test together with the initial tracer test as well as both model fits. The analysis shows an effective pore volume of $660 \pm 30[\mathrm{ml}]$ (porosity $=33 \pm 3 \%$ ) and a dispersion coefficient of $2.7 \pm 1.8 \times 10^{-4}\left[\mathrm{~cm}^{2} / \mathrm{s}\right]\left(N_{P e}=133 \pm 46\right)$. The results are statistically not very different from the initial tracer test, indicating that the pore morphology has not been significantly altered. 


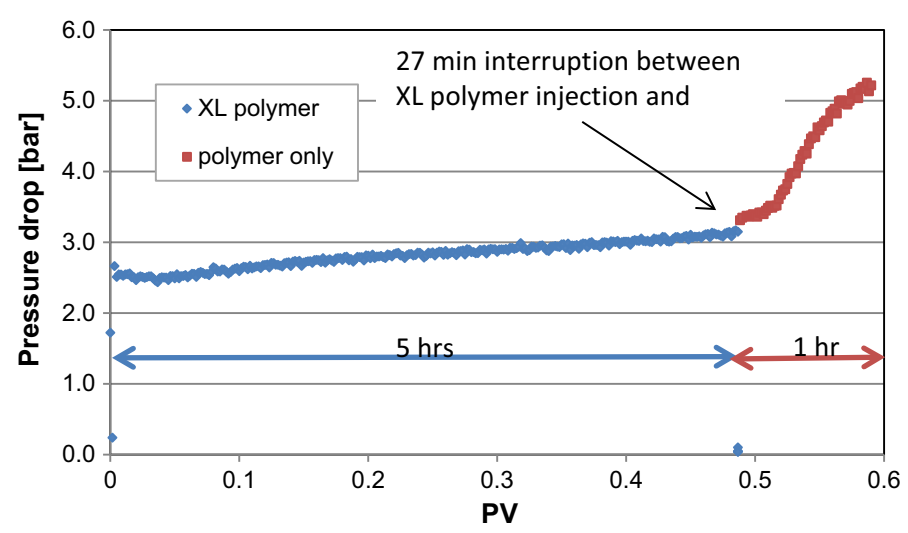

Fig. 14 Pressure drop recorded during XL polymer injection and the polymer follow-up at $1 \mathrm{ml} / \mathrm{min}$

\subsection{Polymer Injection into the Core}

With the core now fully prepared, we injected a $0.5 \mathrm{PV}$ slug of the XL polymer at a flow rate of $1 \mathrm{ml} / \mathrm{min}$ (reproducing the conditions in the near well-bore region). The XL polymer slug was pushed further into the core by a $0.1 \mathrm{PV}$ polymer only slug (Fig. 14).

During the XL polymer injection, only a modest pressure increase took place. However, during the short polymer chase the pressure drop built up quickly, indicating that cross-linking started to have an effect. This happened much faster than expected from the bulk results. Subsequently, we shut the core into allow the cross-linker to do its work. The absence of the shear stimulates the growth of cross-linked agglomerates which block the core. Similar behaviour of the cross-linking polymer under shear flow was studied by Omari et al. (2003) who demonstrated the shear rate dependence of gelling kinetics. They revealed that at high shear rates the polymer aggregates are small, whereas at low shear rates much larger aggregates are formed.

At various intervals, we briefly flow the polymer solution through the core at a rate of $0.12 \mathrm{ml} / \mathrm{min}$ to assess the change in mobility (Fig. 15). The mobility reduction increases almost linearly the first $400 \mathrm{~h}$ to roughly a factor of $7.5^{1}$ measured over the core compared to the XL-free polymer. After this, it appears to stabilize suggesting that no more cross-linker is available.

\subsection{Effect of Cross-Linking in Porous Media}

Despite the effective delay of the cross-linking in bulk, the results of the core flood experiment show that the increase in the pressure drop is observed within hours from the beginning of the XL polymer injection (Figs. 14, 15). The overall bulk viscosity initially is not considerably affected by the creation of small aggregates. However, as they grow over time interactions between the aggregates start to sharply increase the viscosity (McCool et al. 1991; Todd et al. 1993). In order to connect this to the porous media viscosity, a series of filtration tests was carried out using isopore filters with an average pore size of $1.2,5$ and $10 \mu \mathrm{m}$, respectively. The size of the pores in a filter influences the resistivity towards the flow of the Xl polymer. The smaller the size of the pores, the higher the resistivity and the time it takes to filter the

${ }^{1}$ For XL-free polymer injection at a $0.12 \mathrm{ml} / \mathrm{min}$ flow rate, a pressure drop of 0.56 [bar] was measured, corresponding to an in situ viscosity of $1.2 \times 10^{2}[\mathrm{cP}]$. 


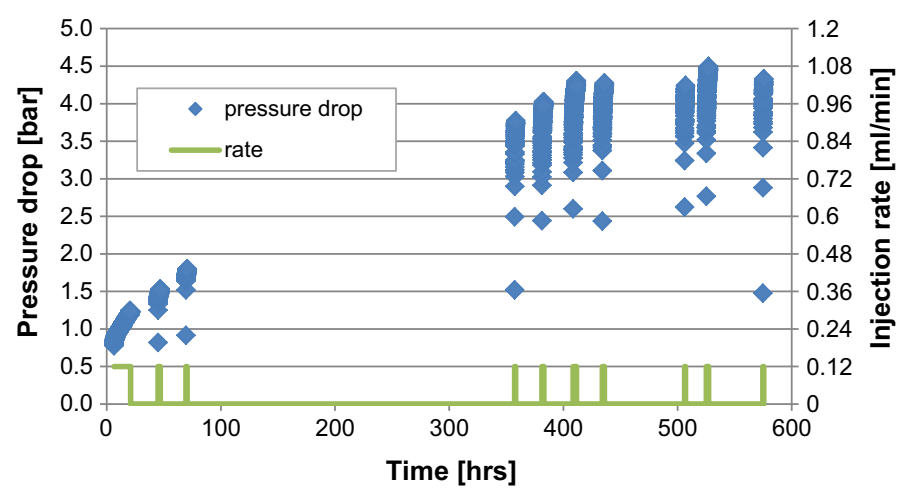

Fig. 15 Several brief intervals of polymer injection probe the changing mobility reduction in the core

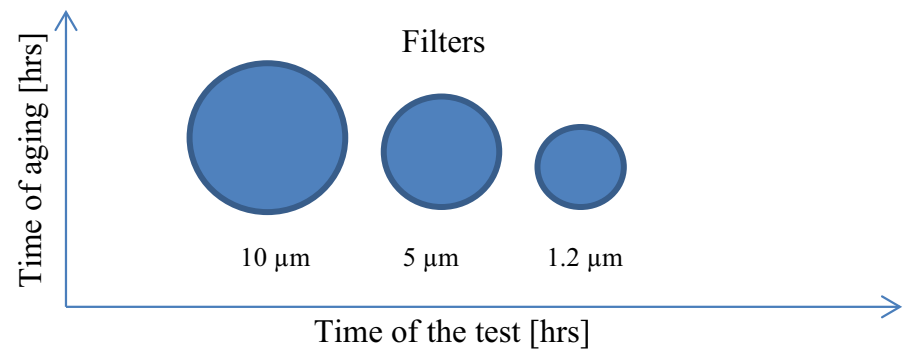

Fig. 16 Workflow of the filtration test

fluid. During the cross-linking process, the size of colloid particles increases and they block the pores of the filter. For example, it took $5.3 \mathrm{~h}$ to filter $50 \mathrm{~g}$ of the cross-linking polymer through a $1.2-\mu \mathrm{m}$ filter after $22.5 \mathrm{~h}$ of ageing, whereas it took $19 \mathrm{~min}$ to filter $80 \mathrm{~g}$ of the cross-linking polymer through a 5- $\mu \mathrm{m}$ filter. Thus, to optimize the time of the filtration ratio tests, we adjusted the volumes of the fluids. In our study, the filtration tests were carried out to filter $180 \mathrm{~g}$ of the fluid through a $10-\mu \mathrm{m}$ filter; $80 \mathrm{~g}$ through $5 \mu \mathrm{m}$ and $50 \mathrm{~g}$ through $1.2 \mu \mathrm{m}$. After the ageing of the cross-linking polymer, an injection of the polymer through different filters is repeated again. Eventually, a set of tests was collected to plot a graph which represents the time of the filtration tests at different ageing times (Fig. 16).

The filtration test experiments show that filters get plugged earlier than gelation is observed in bulk (Fig. 17). The smaller the size of the filter, the earlier it gets plugged by the crosslinked agglomerates. As an example, after $46.5 \mathrm{~h}$ of ageing, the XL polymer hardly flows through the 1.2- $\mu \mathrm{m}$ filter. The test was aborted after $10 \mathrm{~h}$ and the results extrapolated. To obtain a conservative estimate, we used linear extrapolation of the data resulting in $17.5 \mathrm{~h}$. Using a power law extrapolation instead would have yielded $55 \mathrm{~h}$.

Figure 17 shows that the increase in the time of the filtration test within the period of ageing from 5 to $22.5 \mathrm{~h}$ is 5.5 times for $1.2-\mu \mathrm{m}$ filter and 1.25 times for $5 \mu \mathrm{m}$. However, the increase in the bulk viscosity (Fig. 8) for that period of the experiment is negligible and is within the error margin.

The modest increase in pressure during the initial stage of the XL polymer injection can be explained by the formation of gel aggregates as well. The evidence for this hypothesis is 


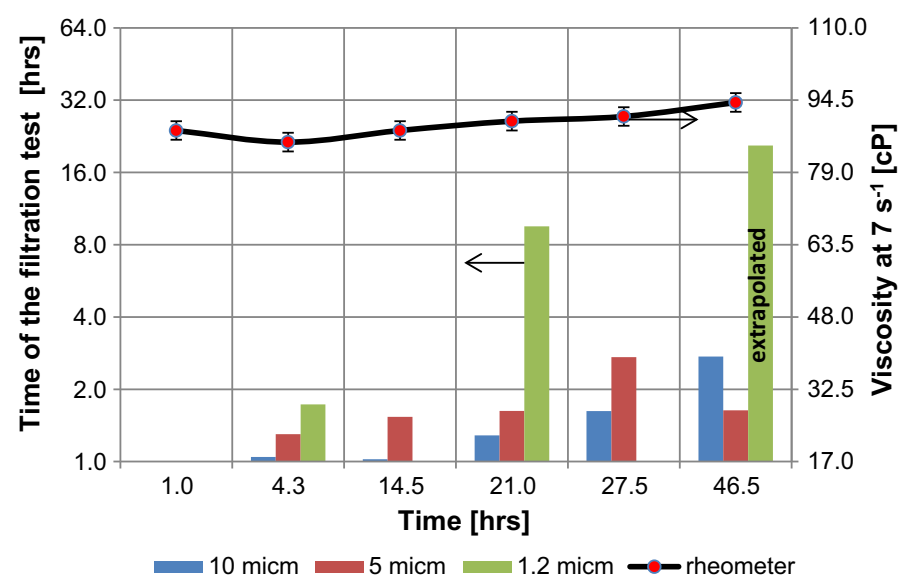

Fig. 17 Combined filtration and rheology tests for the XL polymer

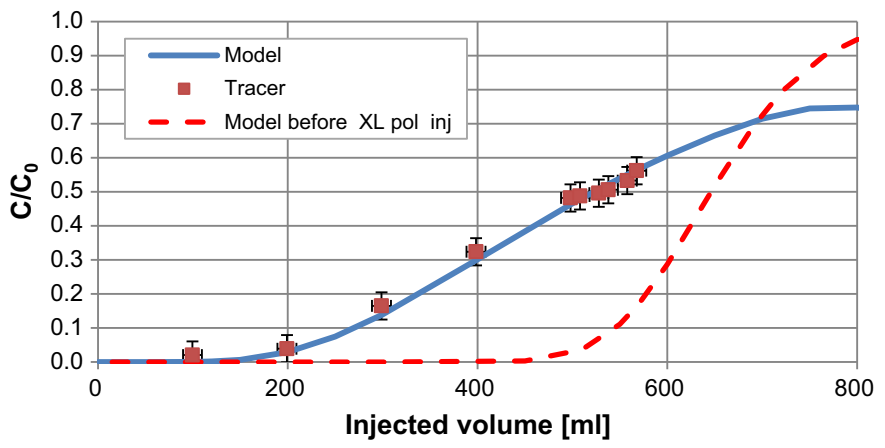

Fig. 18 Tracer data after XL polymer injection

illustrated in the filtration test. Indeed, as shown in Fig. 17, after $5 \mathrm{~h}$ of ageing, the time of the filtration test increased by 1.7 times $(1.2 \mu \mathrm{m}$ filter $)$.

\subsection{Tracer Test After XL Polymer Injection}

The pressure drop displayed above confirms that cross-linking occurred in the core. To assess the associated changes in pore morphology, we again ran a tracer test. This time we injected brine with HPAM and KI (1000 ppm) for 0.95 PV followed by 1 PV (initial porous volume) without the tracer (Fig. 18, red squares). As is clearly evident from Fig. 18 (compared to Fig. 13), breakthrough happens significantly faster. The model match (blue line) yields the following estimates: effective pore volume of $534 \pm 12[\mathrm{ml}]$ (porosity $=26.8 \pm 1.3$ ) and a dispersion coefficient of $56 \pm 11 \times 10^{-4}\left[\mathrm{~cm}^{2} / \mathrm{s}\right]\left(N_{P e}=6.3 \pm 1.6\right)$. Because the tracer-slug size was too small to approach the injection concentration in the effluent, the analytical model was extended by superposition (Pancharoen et al. 2010).

The tracer test indicates a $6.2 \%$ reduction of effective porosity and a 20 times larger dispersion coefficient. 


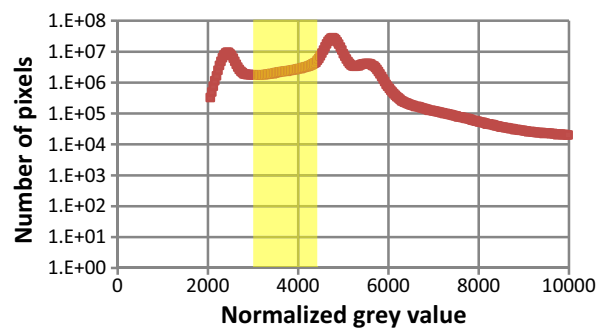

(a)

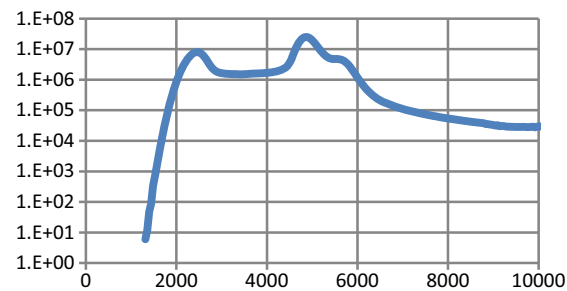

(c)

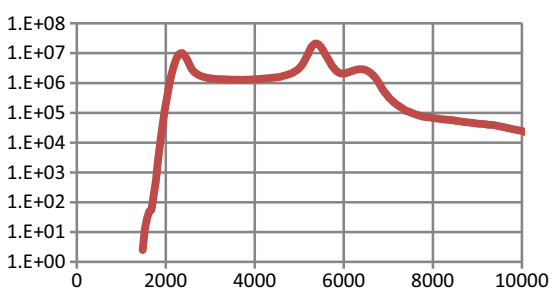

(b)

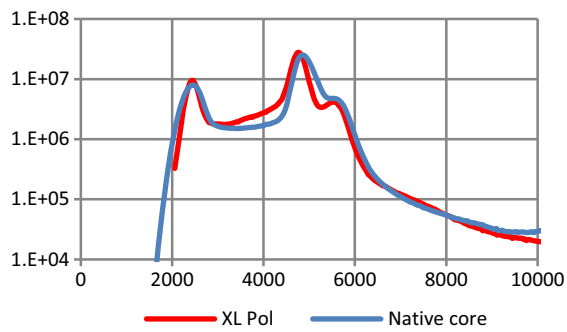

(d)

Fig. 19 Grey value histograms of core plugs: A—sample containing XL polymer; B — the same sample treated with $\mathrm{NaClO}$; $\mathrm{C}$-native Boise core; $\mathrm{D}$ - combined histograms of $\mathrm{A}$ and $\mathrm{C}$

\section{Distribution of the Polymer in the Core}

As shown by the tracer test, the flow characteristics of the core are significantly altered by the cross-linked polymer. In order to determine its in situ distribution, several small plugs were drilled from the outlet section of the $1-\mathrm{m}$ core $(40 \times 10 \mathrm{~mm})$ and scanned using a micro-CT. Subsequently, we immersed the plugs in $\mathrm{NaClO}$ for 7 days, in an attempt to remove the crosslinked polymer, and scanned them again. Figure 19 shows the grey value histogram before (A) (with XL polymer), after (B) (without) and the clean sample of the Boise outcrop (C), respectively. The high-density peak indicates rock, whereas the low-density peak represents pore space. There is a clear expression of a medium density area indicated by the yellow band in Fig. 19a that is noticeably absent after the $\mathrm{NaClO}$ flush (Fig. 19b). This suggests that it corresponds to the XL polymer. It is also important to notice that the histogram of grey value distribution for the clean sample (C) is similar to the histogram for the sample treated with $\mathrm{NaClO}(\mathrm{B})$.

Reconstruction of the initial micro-CT scan with the segmentation (high-rock, medium-XL polymer and low density_-porosity) suggested above yields a 3D image of the plug (Fig. 20).

As can be seen from these images, many of the smaller pores are filled with XL polymer. Calculation of the volumes corresponding to different grey intensities was done using the multi-thresholding and label analysis modules of Avizo (Avizo User's Guide 2015) (Table 4).

From the calculated data (Table 4), we can see that due to the treatment of the core with the XL polymer, porosity was reduced from 32 to $25.8 \%$ which is in reasonable agreement with the tracer data from the full core experiment. This lends credence to the segmentation choices outlined above. 


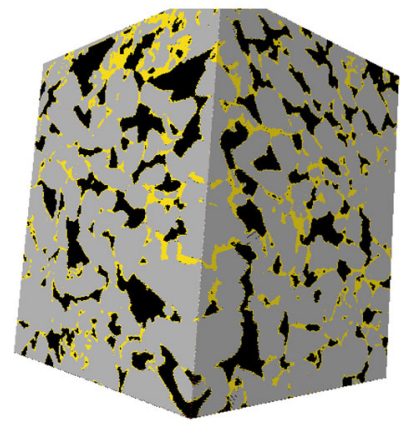

(a)

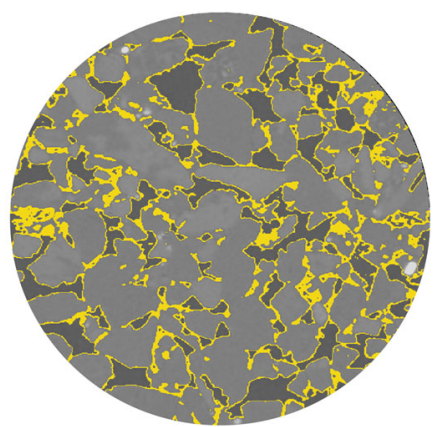

(b)

Fig. 20 a $3 \mathrm{D}$ reconstruction and $\mathbf{b} 2 \mathrm{D}$ slice of the plug showing the pore space as black and XL polymer in yellow

Table 4 Results of the image analysis
Absolute porosity, \%

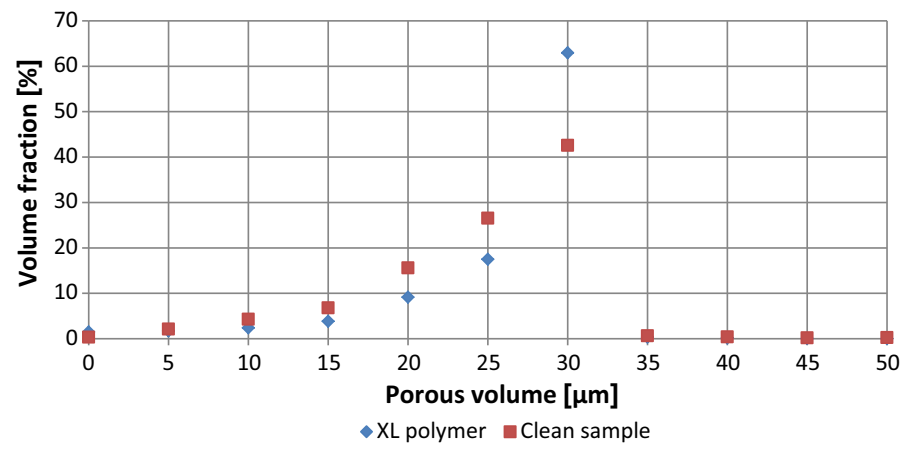

Fig. 21 Pore size distribution of the Boise core before and after the injection of the XL polymer

The blockage of the smaller pores by the XL polymer is also confirmed with pore size distribution in the Boise core before and after the injection of the XL polymer (Fig. 21). From the analysis of the pore size distribution, it is clear that the XL polymer blocks mostly pores within the range from 0 to $25 \mu \mathrm{m}$, whereas bigger pores from 25 to $30 \mu \mathrm{m}$ stay unaffected.

\subsection{Pore-scale Modelling of a Tracer Flow in 3D Micro-CT Images of the Core Samples}

The influence of the cross-linking polymer on the flow characteristics of the core was also studied with the simulation of tracer flow in 3D micro-CT images of core samples ( $40 \mathrm{~mm} \times$ $10 \mathrm{~mm}$ ). It is assumed that the XL polymer creates several preferential flow paths in porous media which increase the dispersion coefficient. Thus, it can be studied via the simulation of the tracer flow in a micro-CT image. Histograms of grey value distribution in the 3D images allowed for depicting the XL polymer in porous media, as well as distinguishing between 


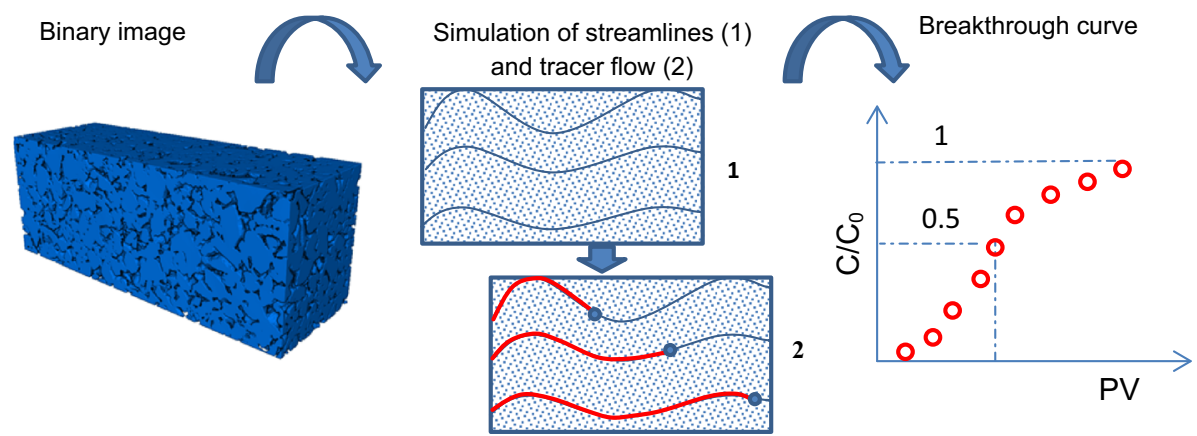

Fig. 22 Workflow of the pore-scale modelling

void and rock space (Russ 2011). The thresholded micro-CT image is converted to a binary image which consists of void and rock space.

The simulation was done in the AddiDict module of the Geodict simulator (Math2Market $\mathrm{GmbH}$ ). As a result of the simulation, the tracer breakthrough curve through the image was obtained. By fitting the analytical 1D convection-dispersion solution (Eq. 2) through the simulated tracer breakthrough curve, the dispersion coefficient was calculated. The exercise of obtaining binary images of rock samples with the following simulation of the tracer flow through the image was done for two core samples: clean core and core affected with the XL polymer. Results of the simulation were compared (Fig. 22).

The modelling of tracer flow is done by firstly computing incompressible, stationary and Newtonian flow through a 3D image of the core sample (Koroteev et al. 2014). Later, when the flow streamlines are obtained, tracer is injected. During the simulation of tracer flow, the following assumptions are made: tracer particles start velocity is equal to the fluid velocity; particles are released at once; tracer concentration does not affect the fluid flow behaviour; molecular diffusion of tracer particles is taken into account; mass transport is controlled by the flow field.

Computed breakthrough curves through the Boise core samples with the XL polymer and the clean core sample are shown in Figs. 23 and 24. The results of the simulation demonstrate that the dispersion coefficient of the Boise core sample after it was treated with the XL polymer is equal to $4.58 \times 10^{-06} \mathrm{~cm}^{2} / \mathrm{s}$, which is 2 times higher than the dispersion coefficient obtained for the clean Boise core. The difference in the dispersion coefficients between the simulation and the core flood experiment can be explained by the difference in the scale of the study. From Fig. 24, it can be seen that the porous volume of the core treated with the XL polymer reduced and the breakthrough happened earlier than for the clean sample. These results confirm that the XL polymer creates a few dominant flow paths which make the flow more heterogeneous.

\subsection{Conclusions}

In addition to studying the cross-linking process in bulk, we demonstrated its behaviour at the core scale ( $1 \mathrm{~m}$ length) as well as on the pore scale. The gelation time in bulk suggested that the PEC could effectively delay the time of the cross-linking even at high brine mineralization. However, the delay experienced in the core flood experiment was much shorter. The early increase in the differential pressure observed in the core flood experiment can be explained by the mechanical entrapment of formed gel particles. The filtration test showed that the growth 


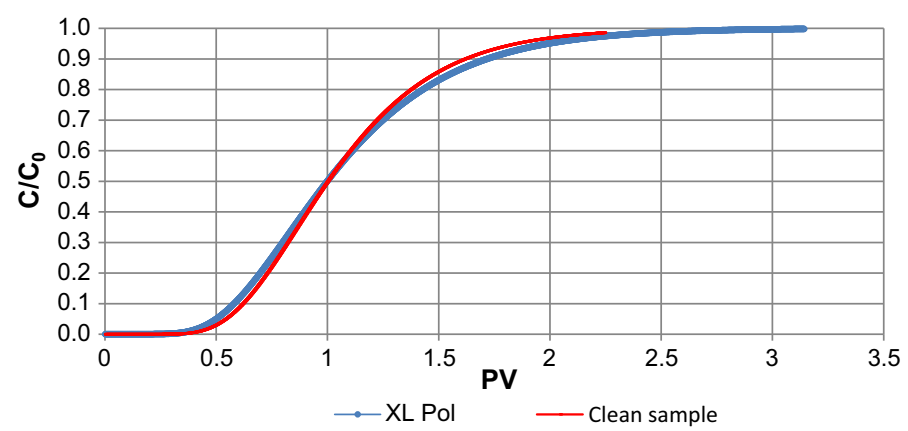

Fig. 23 Breakthrough curves through binary images of the Boise core samples (with the XL polymer and the clean Boise core): $C / C_{0}$ versus dimensionless porous volume

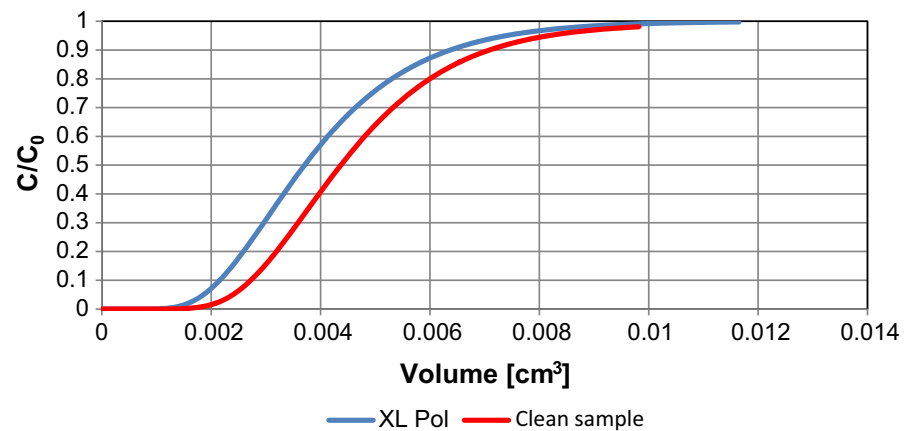

Fig. 24 Breakthrough curves through binary images of the core samples: $C / C_{0}$ versus volume $\left(\mathrm{cm}^{3}\right)$

of the particles is observed over time. This suggests that bulk gelation experiments may not be relevant for use in porous media. Filtration tests offer a much more useful alternative to the conventional bulk gelation tests. Tracer tests demonstrated that the XL polymer reduced the pore volume by roughly $6 \%$ (in absolute terms). The micro-CT images showed that most of the XL polymer was retained in the smaller pores of the core. The large increase in dispersion coefficient suggests that this must have resulted in the creation of a few dominant flow paths isolated from each other by closure of the smaller pores.

The AddiDict simulation showed an increase in the dispersion coefficient by 2 times after the placement of the XL polymer in the core. The results of the study confirm that the XL polymer creates a few dominant flow paths in the core. The difference in the dispersion coefficients between the simulation and the core flood experiment can be explained by the difference in a scale of the study.

Acknowledgements The authors would like to thank Shell Global Solutions International for their support. We are grateful to Menno van Haasterecht and Leandra David for their help in carrying out the core flood experiment. Moreover, we wish to thank Steffen Berg, Wim Verwaal and Joost van Meel for their assistance with the micro-CT scan analysis.

Open Access This article is distributed under the terms of the Creative Commons Attribution 4.0 International License (http://creativecommons.org/licenses/by/4.0/), which permits unrestricted use, distribution, and reproduction in any medium, provided you give appropriate credit to the original author(s) and the source, provide a link to the Creative Commons license, and indicate if changes were made. 


\section{References}

Al-Muntasheri, G.A., Hisham A., Nasr-El-Din, H.A., Zitha, P.L.J.: Gelation kinetics and performance evaluation of organically cross-linked gel at high temperature and pressure. SPE J. 13(3) (2008). http://dx.do i.org/10.2118/104071-PA

Al-Muntasheri, G.A., Zitha, P.L.J.: Gel under dynamic stress in porous media: new insights using computed tomography. In: Paper SPE-126068-MS, Presented at the SPE Saudi Arabia Section Technical Symposium, Al-Khobar, Saudi Arabia, 9-11 May (2009). http://dx.doi.org/10.2118/126068-MS

An, Y., Solis, F.J., Jiang, H.: A thermodynamic model of physical gels. 41 (2010). http://imechanica.org/files /Physical\%20Gel.pdf

Avizo User's Guide.: Avizo 9 (2015). http://www.vsg3d.com

Bailey, B., Crabtree, M., Tyrie, J., Elphick, J., Kuchuk, F., Romano, C., Roodhart, L.: Water control, Oilfiled review (2000)

Batchelor, G.K.: An Introduction to Fluid Dynamics. Cambridge University Press, Cambridge (2000)

Cordova, M., Cheng, M., Trejo, J., Johnson, S.J., Willhite, G.P., Liang, Jenn-Tai, Berkland, C.: Delayed HPAM gelation via transient sequestration of chromium in polyelectrolyte complex nanoparticles. Macromolecules 41(12), 4398-4404 (2008)

Crespo, F., Reddy, B.R., Lewis, C.A., Eoff, L.S.: Recent advances in organically crosslinked conformance polymer systems. In: Paper SPE-164115-MS Presented at the SPE International Symposium on Oilfield Chemistry, the Woodlands, Texas, USA, 8-10 April (2013). http://dx.doi.org/10.2118/164115-MS

Crespo, F., Reddy, B.R., Larry Eoff, L., Christopher Lewis, C., Pascarella, N.: Development of a polymer gel system for improved sweep efficiency and injection profile modification of IOR/EOR treatments. In: Paper IPTC-17226-MS, Presented at the International Petroleum Technology Conference, Doha, Qatar, 19-22 January (2014). http://dx.doi.org/10.2523/IPTC-17226-MS

Dickie, R.A., Labana, S.S., Bauer, R.S.: Cross-Linked Polymers. Chemistry, Properties, and Applications, American Chemical Society (1988). https://doi.org/10.1021/bk-1988-0367

Glasbergen, G., Abu-Shiekah, I., Balushi, S., Wunnik, van J.: Conformance control treatments for water and chemical flooding: material screening and design. In: Paper SPE-169664-MS, Presented at the SPE EOR Conference at Oil and Gas West Asia, Muscat, Oman, 31 March-2 April (2014). http://dx.doi.org/10.21 18/169664-MS

Hove, A.O., Nilse, V., Leknes, J.: Visualization of xanthan flood behavior in core samples by means of X-ray tomography. SPE Reservoir Engineering. SPE-17342-PA (1990). http://dx.doi.org/10.2118/17342-PA

Hutchins, R.D., Dovan, H.T., Sandiford, B.B.: Field applications of high temperature organic gels for water control. In: Paper SPE-35444-MS, Presented at the SPE/DOE Improved Oil Recovery Symposium, Tulsa, Oklahoma, USA. 21-24 April (1996). http://dx.doi.org/10.2118/35444-MS

Jayakumar, S., Lane, R.H.: Delayed crosslink polymer flowing gel system for water shutoff in conventional and unconventional oil and gas reservoirs. In: Paper SPE-151699-MS, Presented at the SPE International Symposium and Exhibition on Formation Damage Control, Lafayette, Louisiana, USA, 15-17 February (2012). http://dx.doi.org/10.2118/151699-MS

Jia, H., Pu, W.-F., Zhao, Jin-Z, Fa-Yang Jin, F.-Y.: Research on the gelation performance of low toxic PEI cross-linking PHPAM gel systems as water shutoff agents in low temperature reservoirs. Ind. Eng. Chem. Res. 49, 9618-9624 (2010). https://doi.org/10.1021/ie100888q

Karsani, K.S.M.E., Al-Muntasheri, G.A., Sultan, A.S., Hussein, I.A.: Impact of salts on polyacrylamide hydrolysis and gelation: new insights. J. Appl. Polym. Sci. 131(23), 1-11( 2014)

Koroteev, D., Dinariev, O., Evseev, N., Klemin, D., Nadeev, A., Safonov, S., Gurpinar, O., Berg, S., van Kruijsdijk, C., Armstrong, R., Myers, M.T., Hathon, L., de Jong, H.: Direct hydrodynamic simulation of multiphase flow in porous rock. Petrophysics 55(3), 294-303 (2014)

Lake, L.W.: Enhanced Oil Recovery. Society of Petroleum Engineers (2010)

Marle, C.: Multiphase Flow in Porous Media. Gulf Publishing, Houston (1981)

McCool, C.S., Green, D.W., Willhite, G.P.: Permeability reduction mechanisms involved in in-situ gelation of a polyacrylamide/chromium (VI)/thiourea system. SPE Reservoir. Eng. J. 6(01), 77-83 (1991). https:// doi.org/10.2118/17333-PA

Moradi-Araghi, A., Stahl, G.A.: Gelation of acrylamide-containing polymers with hydroxyphenyl alkanols. EP Patent 446 865, assigned to Phillips Petroleum Co., September 18 (1991)

Müller, M., Kebler, B., Fröhlich, J., Poeschla, S., Torger, B.: Polyelectrolyte complex nanoparticles of poly(ethyleneimine) and poly(acrylic acid): preparation and applications. Polymers 3, 762-778 (2011)

Omari, A., Chauveteau, G., Tabary, R.: Gelation of polymer solutions under shear flow. Colloids Surf A.: Physicochem. Eng. Aspects 225, 37-48 (2003). https://doi.org/10.1016/S0927-7757(03)00319-4 
Pancharoen, M., Thiele, M.R., Kovscek, A.R.: Inaccessible pore volume of associative polymer floods. In: Paper SPE-129910-MS, Presented at the SPE Improved Oil Recovery Symposium, Tulsa, Oklahoma, USA, 24-28 April (2010). http://dx.doi.org/10.2118/129910-MS

Russ, J.C.: The Image Processing Handbook, 6th edn. CRC Press, Boca Raton (2011)

Saadatfar, M., Arns, C.H., Knackstedt, M.A., Senden, T.J.: Mechanical and transport properties of polymeric foams derived from 3D images. Colloids Surf. A 263(1-3), 284-289 (2005). https://doi.org/10.1016/j.c olsurfa.2004.12.040

Seetha, N., Mohan Kumar, M.S., Hassanizadeh, S.M., Raoof, A.: Virus-sized colloid transport in a single pore: model development and sensitivity analysis. J. Contam. Hydrol. 164, 163-180 (2014)

Seright, R.S., Zhang, G., Akanni, O.O., Wang, D.: A comparison of polymer flooding with in-depth profile-modification. In: Paper SPE-146087-MS, Presented at the Canadian Unconventional Resources Conference, Calgary, Canada, 15-17 November (2011). http://dx.doi.org/10.2118/146087-MS

Sorbie, K.S.: Polymer Improved Oil Recovery. Blackie and Son, Glasgow (1991)

Spruijt, E.: Strength, structure and stability of polyelectrolyte complex coacervates. PhD thesis, Wageningen University, Wageningen, The Netherlands (2012)

Sydansk, R.D., Southwell, G.P.: More than 12 years of experience with a successful conformance-control polymer gel technology. In: Paper SPE-62561-MS, Presented at the SPE/AAPG Western Regional Meeting, Long Beach, California. USA, 19-22 June (2000). http://dx.doi.org/10.2118/62561-MS

Sydansk, R.D.: A new conformance-improvement-treatment chromium (III) gel technology. In: Paper SPE17329-MS, Presented at the SPE Enhanced Oil Recovery Symposium, Tulsa, Oklahoma, USA, 16-21 April (1988). http://dx.doi.org/10.2118/17329-MS

Todd, B.J., Willhite, G.P., Green, D.W.: A mathematical model of in situ gelation of polyacrylamide by a redox process. SPE Reserv. Eng. J. 8(01), 51-58 (1993). https://doi.org/10.2118/20215-PA

Turner, M.L., Knüfing, L., Arns, C.H., Sakellariou, A., Senden, T.J., Sheppard, A.P., Sok, R.M., Limaye, A., Pinczewski, W.V., Knackstedt, M.A.: Three-dimensional imaging of multiphase flow in porous media. Phys. A 339(1), 166-172 (2004). https://doi.org/10.1016/j.physa.2004.03.059

van der Hoek, J.E., Botermans, W., Zitha, P.L.J.: Full blocking mechanism of polymer gels for water control. In: Paper SPE-68982-MS Presented at the SPE European Formation Damage Conference, The Hague, The Netherlands, 21-22 May (2001). http://dx.doi.org/10.2118/68982-MS

van Krevelen, D.W., te Nijenhuis, K.: Properties of polymers, 4th edn. Elsevier, Oxford (2008)

Vasquez, J., Civan, F., Shaw, T.M., Dalrymple, E.D., Eoff, L., Reddy, B.R., Brown, D.: Laboratory evaluation of high temperature conformance polymer systems. In: Paper SPE-80904-MS, Presented at the SPE Production and Operations Symposium, Oklahoma City, USA, 23-26 March (2003). http://dx.doi.org/1 0.2118/80904-MS

Winter, H.H.: Can the gel point of a cross-linking polymer be detected by the $\mathrm{G}^{\prime}-\mathrm{G}^{\prime \prime}$ Crossover? Polym. Eng. Sci. 27(22), 1698-1702 (1987). https://doi.org/10.1002/pen.760272209

Zhang, Q., Zhou, J.: Effect of salt solutions on chain structure of partially hydrolysed polyacrylamide. J. Central South Univ. Technol. 15, 80-83 (2008)

Zitha, P.L.J., Botermans, C.W., van der Hoek, J., Vermolen, F.J.: Control of flow through porous media using polymer gels. J. Appl. Phys. 92, 1143 (2002). https://doi.org/10.1063/1.1487454 